\title{
A Detection Probability Model for Aerial Surveys of Mule Deer
}

\section{Authors: Cody J. Zabransky, David G. Hewitt, Randy W. Deyoung, Shawn S. Gray, Calvin Richardson, Andrea R. Litt, and Charles A. Deyoung}

This is the peer reviewed version of the following article: (See, citation below), which has been published in final form at https://dx.doi.org/10.1002/jwmg.21143. This article may be used for non-commercial purposes in accordance with Wiley Terms and Conditions for Self-Archiving.

Zabransky, Cody J, David G Hewitt, Randy W Deyoung, Shawn S Gray, Calvin Richardson, Andrea R Litt, and Charles A Deyoung. "A Detection Probability Model for Aerial Surveys of Mule Deer." Journal of Wildlife Management 80, no. 8 (November 2016): 1379-1389.

DOI: 10.1002/jwmg.21143.

Made available through Montana State University's $\underline{\text { ScholarWorks }}$ scholarworks. montana.edu 


\title{
A Detection Probability Model for Aerial Surveys of Mule Deer
}

\author{
CODY J. ZABRANSKY, Caesar Kleberg Wildlife Research Institute, Texas AEM University-Kingsville, Kingsville, TX 78363, USA \\ DAVID G. HEWITT, ${ }^{\mathbf{1}}$ Caesar Kleberg Wildlife Research Institute, Texas A\&M University-Kingsville, Kingsville, TX 78363, USA \\ RANDY W. DEYOUNG, Caesar Kleberg Wildlife Research Institute, Texas AEM University-Kingsville, Kingsville, TX 78363, USA \\ SHAWN S. GRAY, Texas Parks and Wildlife Department, Alpine, TX 79830, USA \\ CALVIN RICHARDSON, Texas Parks and Wildlife Department, Canyon, TX 79015, USA \\ ANDREA R. LITT, Department of Ecology, Montana State University, Bozeman, MT 59717, USA
}

CHARLES A. DEYOUNG, Caesar Kleberg Wildlife Research Institute, Texas AङM University-Kingsville, Kingsville, TX 78363, USA

\begin{abstract}
Population estimates derived from aerial surveys of ungulates are biased by imperfect detection, where probability of sighting groups is influenced by variables specific to terrain features and vegetation communities. Therefore, methods for bias-correction must be validated for the region to which they will be applied. Our objectives were to quantify factors affecting detection probability of mule deer (Odocoileus hemionus) during helicopter surveys in Texas, USA, rangelands, and develop a detection probability model to reduce bias in deer population estimates. We placed global positioning system (GPS) collars on 215 deer on 6 sites representative of mule deer range in the southern Great Plains and the Chihuahuan Desert during 2008-2010. We collected data during aerial surveys in January-March and fit logistic regression models to predict detection probability of mule deer based on ecological and behavioral covariates. We evaluated the model using independent estimates of population size derived from a markresight procedure. Detection of mule deer was negatively related to distance from the transect, increasing brush cover, sunlight, and increasing terrain ruggedness $(P<0.01)$. Probability of detection in brush cover was greater if deer were active $(P=0.02)$. Population estimates corrected for visibility bias using our detection probability model or mark-resight models averaged $2.1 \pm 0.49(\mathrm{SD} ; n=50)$ and $2.2 \pm 0.62$ times larger, respectively, than uncorrected counts. Estimates of population size derived from the detection probability model averaged $101 \pm 26 \%$ of mark-resight estimates. However, the detection probability model did not improve precision of population estimates, probably because of unmodeled variation in availability of deer during surveys. Our detection probability model is a simple and effective means to reduce bias in estimates of mule deer population size in southwestern rangelands. Availability bias may be a persistent issue for surveys of mule deer in the Southwest, and appears to be a primary influence of variance of population estimates. (C) 2016 The Wildlife Society.
\end{abstract}

KEY WORDS Chihuahuan Desert, mark-resight, population estimation, sightability, southern Great Plains, Texas, visibility bias.

Aerial surveys are often used to count large mammals over large geographic areas. Unfortunately, counts are biased low because the visibility of animals is influenced by terrain, vegetation, topography, animal activity, social behavior, and other factors (Caughley 1974, Beasom et al. 1981, DeYoung 1985, Pollock and Kendall 1987, Samuel et al. 1987). Counts could be easily adjusted if visibility bias was consistent, but the proportion of the population observed often varies widely. For instance, the proportion of marked white-tailed deer (Odocoileus virginianus) observed during repeated surveys in rangelands of southern Texas, USA, varied from 17-75\% (Beasom et al. 1986).

Without a means to account for probability of detection, changes in annual population counts could be due to an actual change in population size, a change in detection probability, or both (Williams et al. 2002). Experienced observers understand that annual variation in population estimates often is the result of variable detection probability and not necessarily the result of population growth or decline. Nonetheless, accounting for variation in count data is a consistent and vexing problem for managers. Consecutive years of surveys are needed to track population trends, but count data often have low power to detect large changes in population size and cannot be statistically compared (Carpenter et al. 2003, Keegan et al. 2011). These limitations 
hamper the ability of managers to respond to variation in recruitment or survival, or assess the effects of habitat manipulations and other factors on population performance.

Reliance on uncorrected surveys is of special concern for mule deer (O. hemionus), which have experienced range-wide declines in population size and loss of habitat (Gill 2001, Walker 2011, Bergman et al. 2015). Furthermore, population management that is scientifically defensible is increasingly demanded by the public (Freddy et al. 2004, Keegan et al. 2011) and requisite for the cooperative management of natural resources across state and national borders. Marking a portion of the population and conducting surveys to obtain ratios of marked to unmarked animals provides reliable population estimates. However, the logistics and expense of marking large numbers of animals over broad areas makes application of mark-resight techniques difficult in surveys typically conducted by state wildlife agencies (Bartmann et al. 1987). Application of detection probability models, also known as sightability models (Samuel et al. 1987, Steinhorst and Samuel 1989), is an alternative population estimation procedure that does not involve marking animals. Detection probability models have been used to correct for visibility bias during surveys of elk (Cervus elaphus; Anderson et al. 1998, Cogan and Diefenbach 1998, Bleich et al. 2001) and other large mammals in the western United States (Bodie et al. 1995, Anderson and Lindzey 1996, Unsworth et al. 1999, Rice et al. 2009, Jacques et al. 2014). Variables commonly found to influence detection probability include vegetation cover type, animal activity, group size, background color (e.g., snow, green vegetation, brown vegetation, soil), and distance from the survey transect. After an initial study to quantify variables that influence detection probability using radio-marked animals, users can estimate detection probability without the need for marked animals (Samuel et al. 1987).

The performance of detection probability models relies on sound empirical estimates of detection probability generated under similar conditions as actual surveys (Steinhorst and Samuel 1989). Models developed previously for mule deer in the northern Rocky Mountains (Ackerman 1988, Unsworth et al. 1999) are not representative of conditions in the arid southwestern portion of the species' range because of differences in habitats, snow conditions, and group sizes. For instance, mule deer in Texas do not congregate in large herds on winter ranges, and snow cover is rare during surveys. Because detection probability models have not been developed for mule deer in rangelands of the southwestern United States, the objective of our study was to develop and test a detection probability model for aerial surveys of mule deer in this region.

\section{STUDY AREA}

We conducted our study on 6 sites representative of the major vegetation communities encountered during mule deer surveys in Texas. Study sites averaged $30 \mathrm{~km}^{2}$ and were located in the Trans-Pecos (4 sites: TP1, TP2, TP3, TP4) and Panhandle regions (2 sites: PH1, PH2; Fig. 1) of Texas, USA. Elevation in the Trans-Pecos region was 750$2,500 \mathrm{~m}$ and topography ranged from flat and gently rolling to steep, rugged mountains. Vegetation communities were

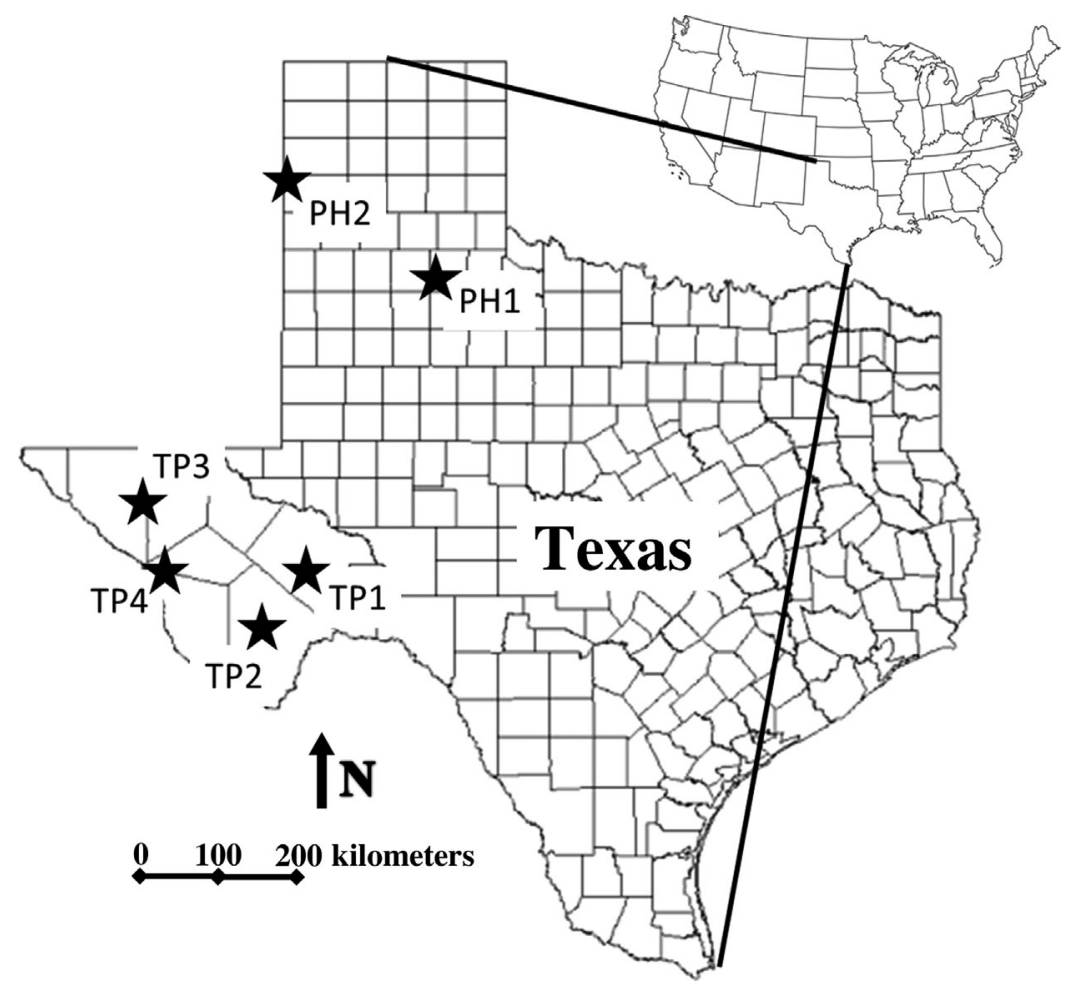

Figure 1. Study sites used to develop detection probability models for helicopter surveys of mule deer in the Trans-Pecos (TP) and Panhandle (PH) regions of Texas, USA. 
primarily Chihuahuan desert grass and shrublands interspersed with juniper (Juniperus spp.) and pinyon pine (Pinus spp.) forests. White-tailed deer (TP1, PH1), pronghorn (Antilocapra americana; TP3, TP4, PH2), and bighorn sheep (Ovis canadensis; TP3) were present on some sites. Summers were hot $\left(32-40^{\circ} \mathrm{C}\right)$, winters were mild $(-5$ to $10^{\circ} \mathrm{C}$ ), and average annual precipitation varied by location from 17.8-45.7 cm (Cantu and Richardson 1997). One site, TP2, was surrounded with a $2-\mathrm{m}$-tall fence erected to deter mule deer movement; all other Trans-Pecos and Panhandle sites contained only livestock fences (1.2-m tall). The Panhandle region was flat to rolling and elevations ranged from 500-1,400 m. The PH2 site contained a section of the Llano Estacado escarpment, which provided $\leq 100 \mathrm{~m}$ vertical relief. Vegetation was shortgrass prairie with wooded drainages, juniper and pinyon pine forests, and a small amount of agricultural fields planted with winter wheat. The Panhandle climate was characterized by warm summers $\left(30-38^{\circ} \mathrm{C}\right)$ and cold winters $\left(-15\right.$ to $\left.5^{\circ} \mathrm{C}\right)$. Precipitation averaged $45 \mathrm{~cm}$ annually (Cantu and Richardson 1997).

\section{METHODS}

We captured 35-36 adult ( $\geq 1$ year old) mule deer using the helicopter net-gun technique (Webb et al. 2008, Jacques et al. 2009) between 15 December and 10 January on each of 2 study sites annually during December 2007-January 2010 (2 sites/year for 3 years). We captured 20 female and 15-16 male deer on each study site and fitted each deer with a Lotek GPS 3300L collar (Lotek, Newmarket, Ontario, Canada) and plastic livestock ear tags (Allflex, Dallas, TX, USA). Collars recorded global positioning system (GPS) fixes and stored data onboard. Each collar had a very high frequency (VHF) beacon and a timed-release mechanism to facilitate retrieval. We programmed collars to record a location every 5 minutes from $0700-1100$ hours and from 15001900 hours, corresponding to our survey periods. Capture and handling of mule deer were approved by the Institutional Animal Care and Use Committee at Texas A\&M University-Kingsville (protocol 2007-10-11A) and were consistent with the guidelines for research on wild mammals presented in Sikes et al. (2011).

\section{Surveys and Classification of Detection Variables}

We conducted surveys between 1 January and 1 March during 2008-2010. Each study site had a single survey area designed to be about $30 \mathrm{~km}^{2}$ and contain most of the collared deer based on the telemetry locations $<48$ hours prior to surveys. We conducted 8-9 surveys on each survey area, with minor shifts in the specific area surveyed depending on the location of collared deer and weather conditions that influenced the duration of a survey. Observers knew that collared deer were available inside the survey area but not the number of animals nor their location. We flew surveys from sunrise to 1100 hours and from 1500 hours to sunset as long as precipitation and wind conditions were safe, following Texas Parks and Wildlife Department (2007) survey protocols.
We flew 46 surveys using a Robinson R44 (Robinson Helicopter Company, Torrance, CA, USA) and 4 surveys using a Bell Jet Ranger helicopter (Bell Helicopter Textron, Ft. Worth, TX, USA). The pilot flew transects spaced $180 \mathrm{~m}$ apart over the entire survey area, at $15-20 \mathrm{~m}$ above ground level and a targeted ground speed of $80 \mathrm{~km} /$ hour, using an aviation GPS unit (Garmin GPSMap 496, Garmin International, Olathe, KS, USA) in the aircraft for reference. The left-front and right-rear passengers were the primary observers; the pilot served as a secondary observer. All observers had experience flying aerial surveys for mule deer, did not experience motion sickness, and were trained on study protocols before their first flight. The fourth passenger recorded observations and location of groups using a Garmin Rino 530hcx GPS (Garmin International).

For each group sighted, the observer recorded the number, sex, and age class (fawn or adult) of animals, deer activity, distance from transects, vegetation cover type, light conditions, terrain, and identified marked deer via ear tags and collar markings. We classified the first animal detected in the group as inactive (i.e., bedded, standing) or active (i.e., walking, running). We recorded the perpendicular distance between the flight line and the location where the group was first detected in 9.1-m increments out to $91 \mathrm{~m}$. Primary observers estimated perpendicular distances but used laser rangefinders to calibrate their visual distance estimates during the survey. We estimated vegetation cover type (i.e., open, brush) for observed groups visually in a 9-m-radius circle centered on the location of the first animal detected (Anderson and Lindzey 1996, McIntosh et al. 2009). The open cover class included bare ground, agriculture fields, and grasslands; we classified a circle with $>10 \%$ cover of woody species as brush. We recorded light conditions of each survey as sunlight ( $<50 \%$ cloud cover) or cloudy. We classified terrain using features in a $50-\mathrm{m}$-radius circle centered on the group. We classified terrain as flat ( $<5 \%$ slope), rolling ( $5-30 \%$ slopes), or rugged $(>30 \%$ slope). After we completed morning surveys, we located via radio-telemetry marked deer that were in the survey area but not detected during the survey and recorded their group size and composition. We also recorded marked deer detected by the recorder during the survey but not by the observers.

\section{Classification of Predictors for Undetected Marked Animals}

If collared deer were detected by the recorder but not seen by observers, we used predictor attributes estimated by the recorder. Otherwise, we used a geographic information system (GIS; ArcGIS 9.3, Environmental Systems Research Institute, Redlands, CA, USA) database to classify detection probability variables for marked deer that we did not detect during surveys. We first determined deer available for sighting during surveys using the tracking analyst extension of ArcGIS, and included only deer $\leq 91 \mathrm{~m}$ of the transect line as the helicopter passed. Vegetation analysis was based on false-color infrared imagery from the National Agricultural Imagery Program flown during summer 2008 at 1-m 
resolution (U.S. Department of Agriculture, Farm Services Agency 2014). One study site was subjected to mechanical brush control between the time we conducted surveys and 2008; we used 2004 imagery for analysis of this site. Using an unsupervised classification in ERDAS Imagine 9.3 (ERDAS, Norcross, GA, USA), we classified the image into 20-50 land cover classes depending on the spectral diversity of each site. A normalized difference vegetation index model was necessary for the 2004 imagery because the results of the classified photosynthetic index produced more reliable results than the classification of raw imagery. We assigned each land cover class to the cover type classes (open or brush) used during aerial surveys based on knowledge of each study site's vegetative communities and from aerial photo interpretation, then combined like classes to create a cover type map for each study site.

We classified activity of deer as the helicopter passed using changes in the deer's location before and after the helicopter passed. Accuracy of the GPS unit in the collar was $\pm 10 \mathrm{~m}$; we considered collared deer that moved $>20 \mathrm{~m}$ as active. We measured perpendicular distance of each deer from the transect line using the measure tool in ArcGIS 9.3. We calculated percent area of each vegetation cover class in a 9$\mathrm{m}$-radius circle around the location of each deer, and classified cover as brush ( $>10 \%$ woody cover) or open. We assigned a single value for light conditions during each survey unless cloud cover changed during a survey. We assigned a terrain category using ArcGIS and the 10-m National Elevation Dataset (U.S. Geological Survey, Sioux Falls, SD, USA). We buffered locations to a radius of $50 \mathrm{~m}$ and calculated a topographic ruggedness index (Riley et al. 1999) using ArcInfo. We compared index values to visual terrain estimates at known locations recorded during surveys and set criteria for terrain estimates from the index to best fit the index and visual estimates.

\section{Statistical Analyses}

We used data from our marked deer and logistic regression (SAS Institute, Cary, NC, USA) to build models to estimate the probability of detecting a deer as a function of deer activity, distance from the transect, vegetation cover type, light conditions, and terrain. Preliminary analysis indicated there was no difference between the sexes in detection probability. If a group had $>1$ collared deer, we included the group in the database only once to maintain independence of observations. We assessed collinearity among our variables using frequency tables for categorical variables and means comparisons for relationships between categorical variables and distance from the transect. Based on these assessments, we considered all variables in our logistic regression model. Interactions between some covariates were biologically realistic, including interactions between cover and activity, cover and distance, activity and distance, and terrain and distance. Following the rationale of Steidl (2006), we used a backwards stepwise elimination procedure, beginning with the full model (i.e., 5 variables and 4 interactions), removing interaction terms and then individual variables that did not explain sufficient variation in the data $(P>0.05)$. We retained independent variables in the model if they were involved in interactions, irrespective of their $P$-value.

We were able to estimate all attributes for groups not detected during surveys using our GIS and GPS locations of deer, except group size. By locating undetected collared deer after surveys and using collared deer detected only by the recorder, we acquired group size for 97 groups that were not detected by observers during surveys. Group size may influence detection of large mammals during surveys, but our sample of group sizes for undetected groups was not sufficient to assess group size in a detection probability model. As an initial assessment of the influence of group size on detection probability, we compared the distribution of group size for groups detected to groups available but not detected during surveys using plots and chi-square analysis. Because there were $<5$ observations for many group sizes $>10$ deer, we considered all group sizes $>10$ deer as a single category in the chi-square analysis.

\section{Model Evaluation}

To evaluate model performance, we computed an independent estimate of population size using a Poisson log-normal mark-resight model in Program MARK (White and Burnham 1999, McClintock et al. 2009). Because we knew which marked deer were present on the survey area from GPS-collar locations, we censored marked deer that died or that left the study area and fixed $\phi$ (apparent survival) to 1 and both $\gamma^{\prime \prime}$ and $\gamma^{\prime}$ (probability of transitioning to and probability of remaining in an unobservable state) to 0 . We evaluated all models in which $\alpha$ (intercept of mean resight rate), $U$ (no. unmarked deer in the population), and $\sigma$ (individual heterogeneity level) were constant or varied by survey. Because all study areas except TP2 had $\geq 2$ models with some support (Akaike Information Criteria [AIC] calculated by Program MARK; model weights $\geq 0.16$ ), we used model-averaging to derive population estimates for each study site (Burnham and Anderson 2002).

We used Pearson's correlation coefficient to evaluate the relationship between population estimates derived from mark-resight, uncorrected survey counts, and our detection probability model. To assess the effect of our detection probability model on precision of population estimates, we assumed that deer density did not vary during the 4-6-week period when we surveyed each study site. Under this assumption, differences in deer density among repeated surveys of a given population were attributed to differences in detection probability. Detection probability models should account for such differences and thereby reduce variation relative to uncorrected counts. We used density instead of population size to evaluate precision because of variation among surveys in the area surveyed for a given study site (Appendix A). We calculated deer density by dividing the estimated population size from each survey by the area surveyed, using uncorrected counts, and population estimates derived from mark-resight or detection probability models. If the detection probability model increased precision of population estimates, the magnitude of correction should be related to the number of deer detected. In other words, if 
few deer are counted during a survey, detection probability was low and the magnitude of correction should be larger than if many deer are counted on the same study site, assuming a closed population. We calculated correlation coefficients for the relationship between number of deer counted versus the correction due to applying the detection probability model.

As a final evaluation of the model, we assessed 2 behavioral factors that could influence animal availability but could not be addressed by our model. First, deer that do not move and remain in heavy cover may have such a low probability of detection as to be effectively undetectable. Such deer would not be available for correction by a detection probability model because of availability bias, similar to marine mammals that remain underwater for extended time periods (Marsh and Sinclair 1989). Second, deer may display movement bias, moving in such a manner that they remain $>91 \mathrm{~m}$ from the helicopter, or are encountered multiple times during a survey. To evaluate availability bias, we quantified the relationship between the proportion of marked deer that remained inactive in brush cover as the helicopter passed and the uncorrected density of deer estimated on that survey. We quantified the effect of movement bias by computing the number of times marked deer were $\leq 91 \mathrm{~m}$ of the helicopter divided by the number of marked deer on the study area during that survey. For both analyses, we used mixed models with study site as a random effect; we accounted for repeated measurements by including study site as the subject. We selected the best-fit covariance structure based on AIC adjusted for small sample bias (Littell et al. 2006).

\section{RESULTS}

We obtained data from GPS collars on 88 male and 126 female deer. We deployed collars 20-37 days before the first survey and completed surveys during a 26-43 day period, depending on study site. Sixteen collared deer died during the study from predation and vehicle collisions, and 2 collars failed in year 3 .

We flew 50 surveys (8-9 surveys per study site). Area surveyed averaged $28.7 \pm 4.5$ (SD) $\mathrm{km}^{2}$ and varied among study sites from $24-33 \mathrm{~km}^{2}$ because of variation in the distribution of collared deer (Appendix A). Environmental conditions during surveys ranged from calm winds, sunny, and warm $\left(\geq 18^{\circ} \mathrm{C}\right)$, to light snow, windy, and temperatures as low as $-11^{\circ} \mathrm{C}$. Snow did not accumulate on the ground in an amount to justify investigation.

Considering a collared deer residing in the area surveyed during a given survey as a potential data point, we had a potential sample size of 1,305 deer observations during our 50 surveys. However, because of the survey pattern we used, some deer were available to be detected from the helicopter $>1$ time during a survey, resulting in 1,408 observations for logistic regression analysis (Appendix B). Observers counted 6,476 mule deer in 2,961 groups, including unmarked deer. Group size averaged $2.2 \pm 2.0$, had a median of 1 , and ranged from $1-31$. Only $1.3 \%$ of observed groups were $\geq 10$ deer. Percent marked deer detected averaged $42 \pm 16 \%$ and ranged
Table 1. Parameter estimates $(95 \% \mathrm{CI})$ for a detection probability model for mule deer during helicopter surveys ( $n=1,408$ observations) during January-February, 2008-2010, in the Trans-Pecos and Panhandle regions of Texas, USA.

\begin{tabular}{llcc}
\hline Parameter $^{\mathbf{a}}$ & Class & Estimate & $\mathbf{9 5 \%}$ CI \\
\hline Intercept & & -0.066 & $-1.177-0.986$ \\
Activity & Active & 0.494 & $-0.578-1.623$ \\
& Inactive & 0 & \\
Distance & & -0.016 & -0.021 to -0.012 \\
Cover & Open & 0 & \\
& Brush & -1.444 & -2.502 to -0.330 \\
Light & Bright & -0.585 & -0.860 to -0.312 \\
& Cloudy & 0 & \\
Terrain & Flat & 1.455 & $1.069-1.847$ \\
& Rolling & 1.143 & $0.872-1.418$ \\
Activity $\times$ cover & Rugged & 0 & \\
& Active and brush & 1.318 & $0.138-2.450$ \\
& Inactive or open & 0 & \\
\hline
\end{tabular}

a Parameters are activity $=$ deer either active or inactive (standing or bedded); distance $=$ perpendicular distance $(\mathrm{m})$ from the transect line to the group; cover = vegetation cover type (open or brush); light $=$ light conditions (bright or cloudy); terrain = terrain ruggedness (flat, rolling, or rugged).

among surveys from 19-77\%. Mean percent of marked male and female deer detected was $39 \pm 16 \%$ and $45 \pm 15 \%$, respectively. The top mark-resight models did not include a sex effect on detection probability of deer in 5 of 6 study sites; therefore, we conducted all subsequent analyses without regard to sex of the deer.

\section{Detection Probability Model}

The 3 interactions between distance from the transect and cover, terrain, and deer activity did not explain sufficient variation in the data and were removed from our final model $(P \geq 0.35)$. The final model contained an interaction between cover and activity and all 5 variables evaluated (Table 1). Probability of detecting deer was negatively related to distance from the transect and, for deer in brush cover, was

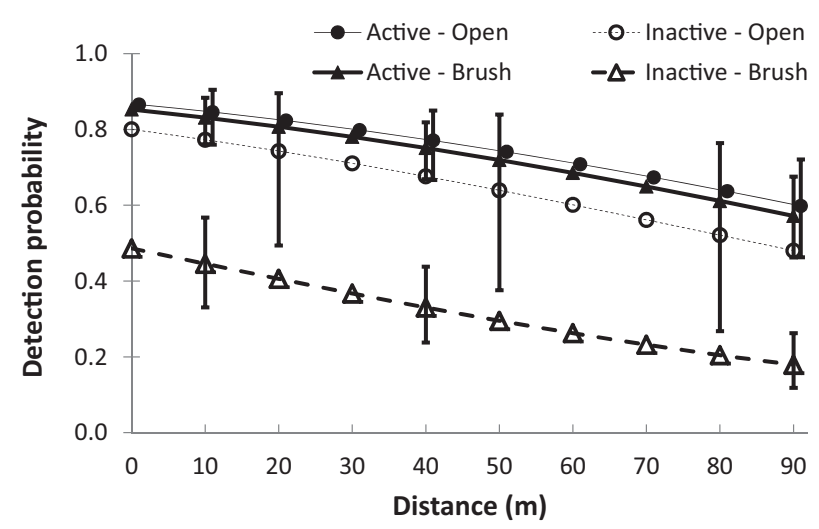

Figure 2. Predicted detection probability (with $95 \%$ prediction intervals on selected estimates) of mule deer as influenced by deer activity (active, inactive), vegetation cover type (open, brush), and perpendicular distance from the survey transect during helicopter surveys in the Trans-Pecos and Panhandle regions of Texas, USA, January-February, 2008-2010. All estimates are for mule deer in cloudy light conditions and flat terrain. Estimates for active deer in open cover type are shifted 1 unit for clarity. 


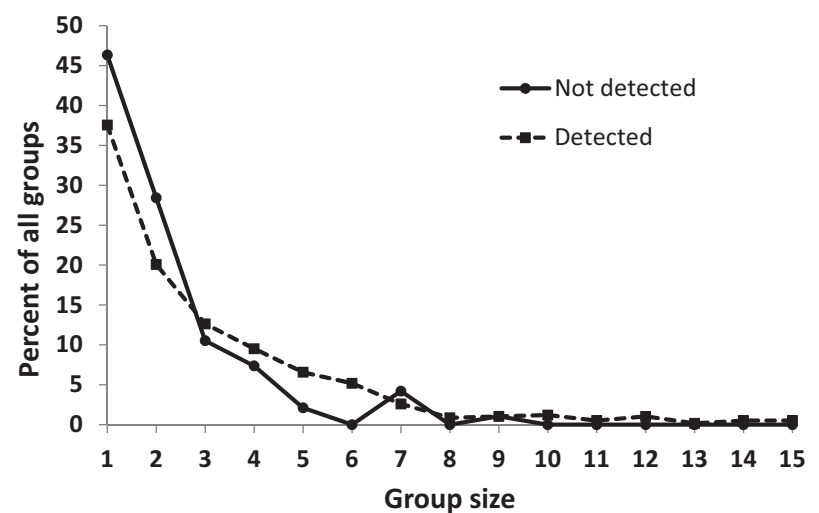

Figure 3. Frequency of group sizes for marked mule deer available that were detected $(n=695)$ and not detected $(n=97)$ during repeated helicopter surveys at 6 study sites in the Trans-Pecos and Panhandle regions of Texas, USA, January-February, 2008-2010.

greater if they were active $(P<0.02$; Table 1 , Fig. 2). Detection probability was negatively related to terrain ruggedness (flat $=0.58,95 \% \mathrm{CI}=0.50-0.67$; rolling $=0.51$, $95 \% \mathrm{CI}=0.47-0.56$; rugged $=0.25,95 \% \mathrm{CI}=0.21-0.30$; setting categorical variables at their reference value and distance from the transect at $50 \mathrm{~m}$ ) and degree of brightness (cloudy $=0.65,95 \% \mathrm{CI}=0.59-0.71$; bright $=0.51,95 \%$ $\mathrm{CI}=0.47-0.56)$. Detection probability on the transect line ranged from $0.11(95 \% \mathrm{CI}=0.07-0.16)$ for deer that were inactive, in bright light, brushy cover, and rugged terrain to $0.87(95 \% \mathrm{CI}=0.79-0.92)$ for active deer in overcast conditions, open cover, and flat terrain.

Our sample of group size for undetected groups (97 groups) was numerically large, but mean group size (2.2) was small and it was only logistically possible to obtain an estimate for $11.7 \%$ of undetected groups. Although our sample of group size for undetected groups was not sufficient to evaluate group size in our detection probability model, the distribution of the size of mule deer groups detected and those not detected suggested that group size requires further investigation as a variable influencing detection probability. The distribution of detected and undetected groups differed by group size $\left(\chi_{9}^{2}=18.0 ; P=0.035\right)$. For groups that were not detected during aerial surveys, $75 \%$ contained $1-2$ deer and

Table 2. Model weights used to generate model-averaged population estimates, by site, based on mark-resight data of mule deer during aerial surveys for 6 study sites in the Trans-Pecos (TP1-4) and Panhandle (PH12) regions of Texas, USA, January-February, 2008-2010. Only the top 4 supported models are shown.

\begin{tabular}{lrrrrrr}
\hline & \multicolumn{6}{c}{ Site } \\
\cline { 2 - 7 } Model description $^{\mathbf{a}}$ & TP1 & TP2 & TP3 & TP4 & PH1 & PH2 \\
\hline$\alpha(t), \sigma(),. U()$. & 0.37 & 0.99 & 0.80 & 0.76 & 0.27 & 0.61 \\
$\alpha(),. \sigma(),. U(t)$ & 0.51 & 0.00 & 0.16 & 0.22 & 0.19 & 0.37 \\
$\alpha(),. \sigma(t), U()$. & 0.01 & 0.00 & 0.00 & $<0.01$ & 0.54 & $<0.01$ \\
$\alpha(t), \sigma(),. U(t)$ & 0.10 & $<0.01$ & 0.05 & 0.01 & $<0.01$ & 0.01 \\
\hline
\end{tabular}

${ }^{\mathrm{a}} \alpha=$ resight rate; $\sigma=$ individual heterogeneity; $U=$ number of unmarked deer; $t=$ parameter varies by time (survey); “.” = null model.
$15 \%$ contained $>3$ deer. In contrast, $30 \%$ of groups that were detected contained $>3$ deer (Fig. 3). Using deer detected by the recorder but not by observers during surveys could have biased our sample of undetected groups if group size influenced detection. The size of undetected groups seen by the recorder was not significantly different from undetected groups located from the helicopter after the survey $(2.9$ vs $\left.2.0 ; t_{18.8}=1.7, \quad P=0.11\right)$. Furthermore, only $21 \%$ of observations (17 of 97) of undetected groups came from the recorder and average group size of all undetected groups only changed from 2.0 to 2.2 with their inclusion. Including groups detected by the recorder improved our assessment of group size because of the larger sample size but also made the test conservative because the larger average group size would have reduced differences in group size between detected and undetected groups.
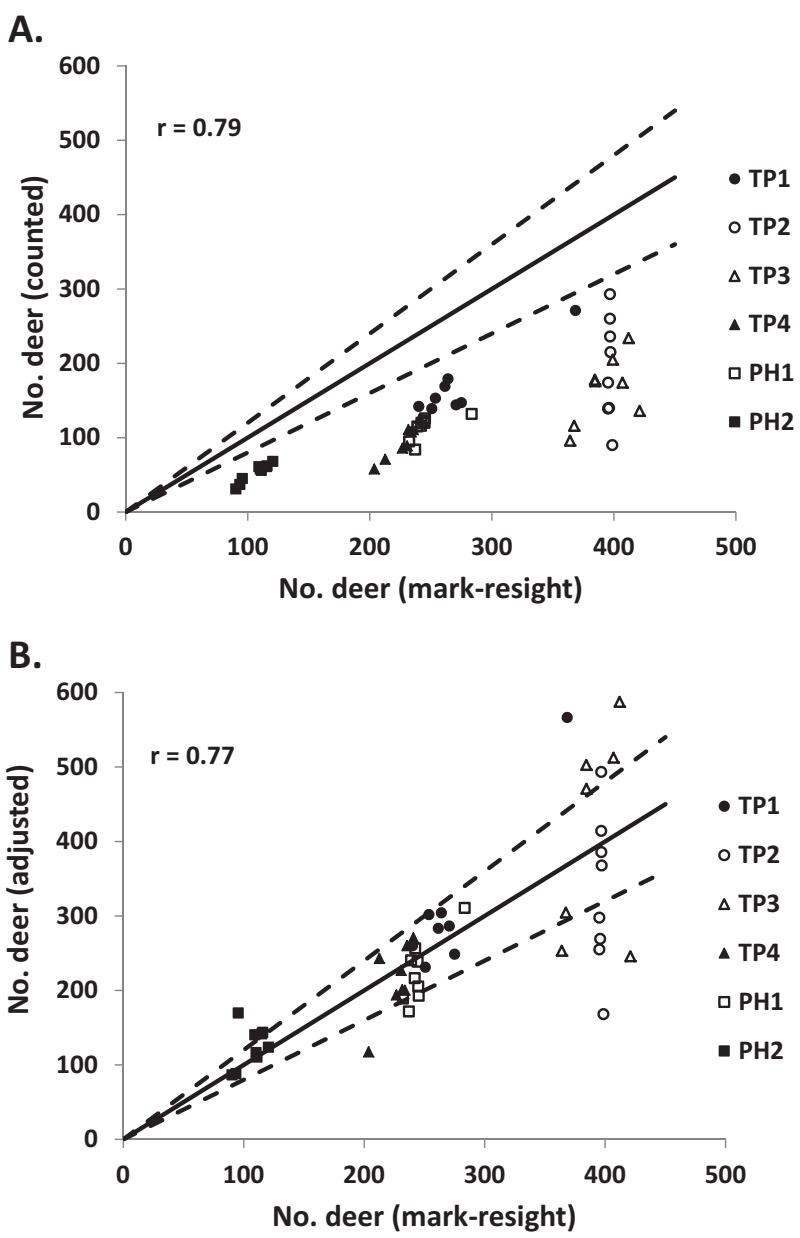

Figure 4. Number of deer estimated during repeated helicopter surveys of mule deer on 6 study sites in the Trans-Pecos (TP1-4) and Panhandle (PH1-2) regions of Texas, USA, January-February, 2008-2010. Estimates are based on mark-resight of radio-collared deer ( $x$ axis) compared to (A) uncorrected number of deer counted and (B) number of deer counted adjusted using a detection probability model. Solid lines show a 1:1 relationship and dashed lines show $\pm 20 \%$ of the equality line. Correlation coefficients show the strength of the relationship between the population estimates. 
Evaluation of the Detection Probability Model

Mark-resight analysis indicated that resight rate, number of unmarked animals in the population, or individual heterogeneity varied among surveys and $>1$ model had some support, with the exception of site TP2 (Table 2). There was support for variation in resight rate among surveys on all study sites, suggesting that visibility of deer varied with survey occasion. The average lowest resight rate was $0.33 \pm 0.12$ and the average highest rate was $0.76 \pm 0.19$ ( $n=6$ sites). The number of unmarked deer also varied among surveys, which may have been influenced by the area flown (Appendix A) and by movement of deer on and off the survey area.

Population estimates from uncorrected surveys averaged $49 \pm 10 \%(n=50)$ of the population estimated using our detection probability model. Correlation coefficients for the relationship between mark-resight population estimates and either uncorrected population counts $(r=0.79)$ or population estimates derived from our detection probability model were similar ( $r=0.77$; Fig. 4). Population estimates from uncorrected surveys and from detection probability models averaged $48 \pm 11 \%$ and $101 \pm 26 \%$, respectively, of those derived from mark-resight estimates.

Our detection probability model did not improve precision relative to uncorrected counts of deer. The coefficient of variation $(\mathrm{CV})$ from repeated counts using estimates from the detection probability model averaged $17 \%$ greater than for uncorrected density estimates and standard deviation increased over 2-fold (Table 3). Mark-resight population estimates had greater precision, and CV averaged $50 \%$ of that from uncorrected density estimates. Within a study area, the magnitude of correction in population size derived from our detection probability model was not clearly related to the number of deer counted during a given survey (Fig. 5). Correlation coefficients calculated separately for each study site between the correction and the density of deer counted ranged from -0.67 to $0.58(P \geq 0.07)$.

Variation in deer density among surveys on a given study site was weakly related to availability bias (i.e., \% of deer inactive in brush cover; parameter estimate $=-0.023$,

Table 3. Coefficient of variation (CV) and standard deviation (SD) for estimates of population density derived from repeated surveys of mule deer for uncorrected observations, and observations corrected using mark-resight and a detection probability model for 6 study sites in the Trans-Pecos (TP1-4; $n=8$ surveys) and Panhandle (PH1-2; $n=9$ surveys) regions of Texas, USA, January-February, 2008-2010.

\begin{tabular}{|c|c|c|c|c|c|c|}
\hline \multirow[b]{2}{*}{ Study site } & \multicolumn{2}{|c|}{ Observed } & \multicolumn{2}{|c|}{ Mark-resight } & \multicolumn{2}{|c|}{$\begin{array}{c}\text { Detection } \\
\text { probability } \\
\text { model }\end{array}$} \\
\hline & $\mathrm{CV}$ & SD & $\mathrm{CV}$ & SD & $\mathrm{CV}$ & SD \\
\hline TP1 & 0.30 & 1.80 & 0.18 & 1.77 & 0.35 & 3.95 \\
\hline TP2 & 0.34 & 2.35 & 0.06 & 0.81 & 0.29 & 3.53 \\
\hline TP3 & 0.17 & 0.88 & 0.15 & 2.03 & 0.26 & 3.70 \\
\hline TP4 & 0.26 & 1.02 & 0.12 & 1.16 & 0.26 & 2.28 \\
\hline PH1 & 0.15 & 0.62 & 0.08 & 0.72 & 0.20 & 1.60 \\
\hline PH2 & 0.20 & 0.33 & 0.12 & 0.38 & 0.30 & 1.14 \\
\hline Average & 0.24 & 1.17 & 0.12 & 1.15 & 0.28 & 2.70 \\
\hline
\end{tabular}

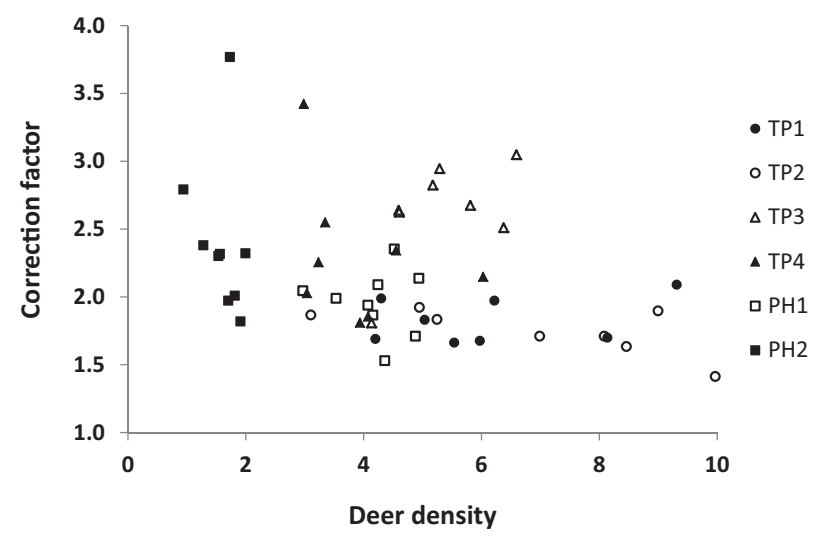

Figure 5. Correction factor derived from the ratio of corrected population size (using a detection probability model) to uncorrected number of deer counted during repeated helicopter surveys of mule deer on 6 study sites in the Trans-Pecos (TP1-4) and Panhandle (PH1-2) regions of Texas, USA, January-February, 2008-2010. The $x$-axis is deer density calculated from uncorrected number of deer counted divided by the area surveyed.

$\mathrm{SE}=0.013, P=0.08$ ). Our analysis suggested we counted fewer deer as proportion of hidden deer increased, but the effect size was small. The percent of collared deer classified as potentially hidden across all surveys ranged from $0-52 \%$. Thus, our hidden-deer variable could explain variation in deer density no larger than $1.2 \mathrm{deer} / \mathrm{km}^{2}$ (derived by multiplying the coefficient from the relationship, -0.023 , by the largest percent of potentially hidden deer, $52 \%$ ), even though deer density ranged $\leq 7 \mathrm{deer} / \mathrm{km}^{2}$ among surveys of a given site ( $x$-axis, Fig. 4$)$. There was stronger evidence that deer movements, resulting in either deer avoiding the helicopter entirely or being available to be seen more than once, were related to variation in deer density across multiple surveys of a given study area (parameter estimate $=1.81$, $\mathrm{SE}=0.68, P=0.01$ ). Our index of deer movement varied from 0.74 (i.e., marked deer moved in such a way as to avoid the helicopter) to 1.62 (i.e., marked deer moved in such a way as to be available to be seen 1.6 times each). Because the median deer movement index was 1.1, double-counting animals appeared to be a more important problem than deer moving in such a manner as to not be within $91 \mathrm{~m}$ of the helicopter. Collared deer moved in such a manner as to avoid the helicopter (i.e., deer movement index $<1$ ) in $30 \%$ of our surveys.

\section{DISCUSSION}

Detection probability models are used to address negative bias in population estimates derived from aerial surveys (Samuel et al. 1987). Applying our detection probability model resulted in population estimates that were double that of uncorrected surveys, and therefore reduced bias in aerial surveys for mule deer in the Chihuahuan Desert and southern Great Plains. Previous studies of detection probability have reached conflicting conclusions about the importance of vegetation cover type, depending on the species and habitats involved (Biggins and Jackson 1984, Gasaway et al. 1985, Anderson and Lindzey 1996, Cogan 
and Diefenbach 1998, Allen et al. 2005). Cover type was a significant factor influencing detection probability in our study, reinforcing the need to develop detection probability models in the habitats to which they will be applied. Activity had a large potential to affect detection probability because only $15 \%$ of collared, inactive deer were detected during the study, compared to $50 \%$ of active deer. For the model to correct for low detection probability of inactive deer, at least some inactive groups need to be detected during surveys. Our detection rate of inactive groups was 0.59 groups $/ 100 \mathrm{~km}$ of transect and thus hundreds of kilometers of transect must be flown to reasonably account for inactive deer. Animal activity was a factor influencing detection probability from the helicopter for some (Gasaway et al. 1985, Ackerman 1988, Anderson et al. 1998, Allen et al. 2005), but not all studies (Samuel et al. 1987, Anderson and Lindzey 1996, and Cogan and Diefenbach 1998). Anderson et al. (1998) noted that activity may not influence detection probability during surveys with snow cover, but activity may be important during surveys with no snow cover. An analogous interaction occurred in our results in which animal activity influenced detection probability more in brush than in open cover.

Detection probability was greater in cloudy conditions, similar to the findings of Allen et al. (2005) but not Anderson and Lindzey (1996). Our study design did not allow us to verify the underlying cause of sunlight effects. However, bright sunlight increased the contrast between sunny and shady areas, potentially reducing the ability of observers to detect deer in the shade. Furthermore, morning and evening sunlight caused $\geq 1$ observer to look into the sun, whereas other observers may have been affected by glare on the helicopter windows.

As in other studies of aerial deer surveys (DeYoung et al. 1989, White et al. 1989), detectability of deer declined with distance from the flight path. However, our data and other studies suggested that distance sampling alone would not be a viable technique to correct for undetected groups of deer because not all deer on the flight transect are observed (DeYoung et al.1989, White et al. 1989), thus violating a key assumption of distance sampling (Burnham et al. 1980). As with detection probability models, distance sampling can not address the problem of availability bias resulting from animals whose probability of being seen is near zero. One reason distance from the transect has not been reported as an important variable in detection probability models is that methods used by other studies often did not allow measurements of distance from the transect for animals that were not detected.

Our study used location data collected from GPS collars to identify cases of missed detection and is one of the few studies using fine-scale GPS location data in development of detection probability models. Deploying GPS collars on 214 deer provided a large sample size and detailed information about deer movement and location during surveys. Whereas many other studies obtained information on undetected animals after the survey was completed (Samuel et al. 1987, Anderson et al. 1998, McIntosh et al. 2009), we were able to analyze location data taken every 5 minutes. As a result, we were able to incorporate variables such as distance from the survey transect and deer activity. We also were able to use multiple re-sighting opportunities of deer whose movements intersected survey transects $>1$ time during a survey and to exclude animals that were not available for detection because their movements during the survey caused them to be located $>91 \mathrm{~m}$ from the helicopter. Both situations would have been difficult to address using VHF radio-collared or ear-tagged deer and could bias coefficients in detection probability models if not accounted for.

Although GPS technology was an excellent tool in data collection, our sample of marked deer was sufficiently large that we were able to collect group size information only from a proportion of undetected marked deer during each survey. Furthermore, because mean group size was 2.2, there were many potential groups during each survey, and these could not be logistically located in a reasonable amount of time after each survey. Other studies used additional aerial platforms (e.g., fixed-wing aircraft) or ground crews to locate undetected groups concurrent with survey effort (Samuel et al. 1987, Bodie et al. 1995, Rice et al. 2009), but we were unable to do so. Nonetheless, even our limited sample of undetected deer provided evidence that group size influenced detection probability, a finding supported by other studies (Samuel et al. 1987, Ackerman 1988, Anderson and Lindzey 1996, Anderson et al. 1998, Cogan and Diefenbach 1998). Excluding group size from the detection probability model could result in biased population estimates if applied to populations with a distribution of group sizes that differed from those used during model development. For example, populations with larger groups than used in model development, such as might occur in the vicinity of agricultural fields, would result in overestimates because the larger groups are more visible than the average group size used during model development.

Population estimates from repeated aerial surveys of closed populations often are highly variable (Beasom et al. 1986), a phenomenon we encountered. Part of this variation is related to variation in detection probability, which ranged from 0.19-0.77 in our surveys, similar to that reported for whitetailed deer in southwestern rangelands (Beasom et al. 1986). Detection probability models should improve precision of population estimates by accounting for variation in detection probability among surveys. However, our detection probability model had lower precision relative to uncorrected counts. One reason our detection probability model did not improve precision is that, on any given study site, the magnitude of correction from applying the detection probability model was not related to the density of deer counted (Fig. 5). Furthermore, variation in the magnitude of correction (average $\mathrm{CV}=0.15$ ) was small relative to variation in density of deer counted on repeated surveys (average $\mathrm{CV}=0.24$; Table 3) within a study site.

A relatively consistent level of correction may occur because detection probability models can correct only for perception bias (Marsh and Sinclair 1989), which may not vary dramatically when averaged across all the groups of animals detected during a survey. However, some deer may be 
essentially undetectable. This form of detection bias, referred to as availability bias (Marsh and Sinclair 1989), cannot be addressed by detection probability models. Deer that are unavailable because they are hidden (e.g., bedded in brush cover) or because they move outside the survey transect as the helicopter passes contribute to availability bias. DeYoung et al. (1989) reported evidence of undetectable deer during studies with marked white-tailed deer in southern Texas. Differences in availability bias among surveys could add variability to population surveys that cannot be corrected using detection probability models. Our analyses suggest that variation in potentially hidden deer (i.e., deer in brush that do not move as the helicopter passes) and in deer movements could influence availability bias. However, the effect of deer movements was attributed to both deer that moved away from the helicopter and deer that moved in such a manner as to be available for detection more than once during a survey. This latter effect was possible because we flew adjacent, parallel transects. Surveys flown in widely-spaced transects will not be susceptible to such double counting and thus should not be a concern for state agencies surveying deer over large areas. As a conservative recommendation of distance between transects to avoid recounting deer during a single survey, we calculated daily movement of GPS-collared male deer during survey days for 21 surveys. We used males because their daily movements were larger than females. Male mule deer moved an average of $3.9 \pm 0.9 \mathrm{~km} /$ day (range $2.6-6.2 \mathrm{~km} /$ day; $n=21$ surveys), suggesting that transects spaced $4 \mathrm{~km}$ apart would not be susceptible to recounting the same deer during aerial surveys. Finally, factors other than those included in our model, such as group size, may also influence detection probability.

Mark-resight estimates are the best population estimates we had available and we used them as a standard to evaluate uncorrected counts and estimates derived from our detection probability model. Results of mark-resight analysis also provided insight into variation in population estimates among survey occasions on a given study site. Resight rate varied among survey occasions and could represent variation not included in our detection probability model. Movement of deer into and out of the survey areas also may have occurred, causing the number of unmarked animals to vary. We found support for variation in the number of unmarked animals on all study sites except TP2, which was surrounded by a $2-m$-tall fence that clearly defined the area to be flown and restricted (but did not stop) movement of animals into and out of the study site. Finally, collared deer could have responded to the helicopter during surveys differently than deer without collars because collared deer had been previously captured using a helicopter. If this difference in behavior caused collared deer to have a lower resight rate than deer without collars, mark-resight models would have overestimated population size.

Population estimates derived from our detection probability model were an improvement relative to uncorrected counts. Undercounting group size can result in detectionprobability adjusted estimates that are biased low (Cogan and Diefenbach 1998, Walsh et al. 2009). We found no such bias, perhaps because mule deer in our study area do not form large herds during winter $(\bar{x}$ group size $=2.2)$, thus reducing the likelihood of undercounting group size. Mark-resight models provided more realistic population estimates than detection probability models for elk in forests of western Washington, USA because a large proportion of elk had low detection probabilities in the heavily forested study area (McCorquodale et al. 2013). Conversely, mark-resight and detection probability models resulted in similar population estimates for pronghorn in more open habitat of the northern Great Plains (Jacques et al. 2014). Similar to elk in western Washington (McCorquodale et al. 2013), mule deer in Texas rangelands appear to have low and variable rates of detection among repeated surveys. This variation in detection probability explains high count variation in repeated surveys; if this reasoning is correct, availability bias must be addressed to obtain precise population estimates for mule deer in Chihuahuan Desert and southern Great Plains habitats. In practice, availability bias cannot be addressed without marking animals, which requires additional logistical and financial support.

\section{MANAGEMENT IMPLICATIONS}

Relative to uncorrected counts, our detection probability models increase accuracy of aerial surveys for mule deer in the southern Great Plains and Chihuauan Desert. We recommend detection probability models when population surveys using marked animals are infeasible, but recognize further refinement is necessary to improve precision relative to uncorrected counts. Group size may influence detection probablity and thus our detection probability model should not be used if the distribution of group sizes observed differs from that in the populations we sampled $(\bar{x}=2.2 \pm 2.0$ deer/ group, median =1).

\section{ACKNOWLEDGMENTS}

We appreciate the generosity of the landowners on whose property we conducted this study and the observers who contributed to data collection. E. J. Redeker assisted with geospatial analysis. Helpful reviews of earlier versions of this manuscript were provided by G. C. White, A. N. Tri, M. E. Blum, and 2 anonymous reviewers. This is manuscript number 15-112 from the Caesar Kleberg Wildlife Researsch Institute. Texas Parks and Wildlife Department provided financial support for this study.

\section{LITERATURE CITED}

Ackerman, B. B. 1988. Visibility bias of mule deer aerial census procedures in southeast Idaho. Dissertation, University of Idaho, Moscow, USA.

Allen, J. R., E. H. Merrill, L. E. McInenley, and M. S. Boyce. 2005. Elk sightability and stratified surveys with resource selection functions. Deer and Elk Workshop Proceedings 6:43.

Anderson, C. R., and F. G. Lindzey. 1996. Moose sightability model developed from helicopter surveys. Wildlife Society Bulletin 24:247-259.

Anderson, C. R., D. S. Moody, B. L. Smith, F. G. Lindzey, and R. P. Lanka. 1998. Development and evaluation of sightability models for summer elk surveys. Journal of Wildlife Management 62:1055-1066.

Bartmann, R. M., G. C. White, L. H. Carpenter, and R. A. Garrott. 1987. Aerial mark-recapture estimates of confined mule deer in pinyon-juniper woodland. Journal of Wildlife Management 51:41-46. 
Beasom, S. L., J. C. Hood, and J. R. Cain. 1981. The effect of strip width on helicopter censusing of deer. Journal of Range Management 34:36-37.

Beasom, S. L., F. G. Leon, and D. R. Synatzske. 1986. Accuracy and precision of counting white-tailed deer with helicopters at different sampling intensities. Wildlife Society Bulletin 14:364-368.

Bergman, E. J., P. F. Doherty, G. C. White, and A. A. Holland. 2015. Density dependence in mule deer: a review of evidence. Wildlife Biology 21:18-29.

Biggins, D. E., and M. R. Jackson. 1984. Biases in aerial surveys of mule deer. Thorne Ecological Institution Technical Publication 14:60-65.

Bleich, V. C., C. S. Y. Chun, R. W. Anthes, T. E. Evans, and J. K. Fischer. 2001. Visibility bias and development of a sightability model for tule elk. Alces 37:315-327.

Bodie, W. L., E. O. Garton, E. R. Taylor, and M. McCoy. 1995. A sightablity model for bighorn sheep in canyon habitats. Journal of Wildlife Management 59:832-840.

Burnham, K. P., and D. R. Anderson. 2002. Model selection and multimodel inference: a practical information-theoretic approach. Second edition. Springer-Verlag, New York, New York, USA.

Burnham, K. P., D. R. Anderson, and J. L. Laake. 1980. Estimation of density from line transect sampling of biological populations. Wildlife Monographs 72:1-202.

Cantu, R., and C. Richardson. 1997. Mule deer management in Texas. Texas Parks and Wildlife Department, Austin, USA.

Carpenter, L. H., D. Lutz, and D. Weybright. 2003. Mule deer data types, uses, analyses, and summaries. Pages 163-176 in J. C. deVos Jr., M. R. Conover, and N. E. Headrick, editors. Mule deer conservation: issues and management strategies. Berryman Institute Press, Utah State University, Logan, USA.

Caughley, G. 1974. Bias in aerial survey. Journal of Wildlife Management 38:921-923.

Cogan, R. D., and D. R. Diefenbach. 1998. Effect of undercounting and model selection on a sightability-adjustment estimator for elk. Journal of Wildlife Management 62:269-279.

DeYoung, C. A. 1985. Accuracy of helicopter surveys of deer in South Texas. Wildlife Society Bulletin 13:146-149.

DeYoung, C. A., F. S. Guthery, S. L. Beasom, S. P. Coughlin, and J. R. Heffelfinger. 1989. Improving estimates of white-tailed deer abundance from helicopter surveys. Wildlife Society Bulletin 17:275-279.

Freddy, D. J., G. C. White, M. C. Kneeland, R. H. Kahn, J. W. Unsworth, W. J. deVergie, V. K. Graham, J. H. Ellenberger, and C. H. Wagner. 2004. How many mule deer are there? Challenges of credibility in Colorado. Wildlife Society Bulletin 32:916-927.

Gasaway, W. C., S. D. Dubois, and S. J. Harbo. 1985. Biases in aerial transect surveys for moose during May and June. Journal of Wildlife Management 49:777-784.

Gill, R. B. 2001. Declining mule deer populations in Colorado: reasons and responses. Special report 77. Colorado Division of Wildlife, Denver, USA.

Jacques, C. N., J. A. Jenks, C. S. Deperno, J. D. Sievers, T. W. Grovenburg, T. J. Brinkman, C. C. Swanson, and B. A. Stillings. 2009. Evaluating ungulate mortality associated with helicopter net-gun captures in the Northern Great Plains. Journal of Wildlife Management 73:1282-1291.

Jacques, C. N., J. A. Jenks, T. W. Grovenburg, R. W. Klaver, and C. S. Deperno. 2014. Incorporating detection probability into northern Great Plains pronghorn population estimates. Journal of Wildlife Management 78:164-174.

Keegan, T. W., B. B. Ackerman, A. N. Adoude, L. C. Bender, T. Boudreau, L. H. Carpenter, B. B. Compton, M. Elmer, J. R. Heffelfinger, D. W. Lutz, B. D. Trindle, B. F. Wakeling, and B. E. Watkins. 2011. Methods for monitoring mule deer populations. Mule Deer Working Group, Western Association of Fish and Wildlife Agencies, Boise, Idaho, USA.
Littell, R. C., G. A. Milliken, W. W. Stroup, R. D. Wolfinger, and O. Schabenberger. 2006. SAS for mixed models. Second edition. SAS Institute, Cary, North Carolina, USA.

Marsh, H., and D. F. Sinclair. 1989. Correcting for visibility bias in strip transect aerial surveys of aquatic fauna. Journal of Wildlife Management 53:1017-1024

McClintock, B. T., G. C. White, M. F. Antolin, and D. W. Tripp. 2009. Estimating abundance using mark-resight when sampling is with replacement or the number of marked individuals is unknown. Biometrics 65:237-246.

McCorquodale, S. M., S. M. Knapp, M. A. Davison, J. S. Bohannon, C. D. Danilson, and W. C. Madsen. 2013. Mark-resight and sightability modeling of a western Washington elk population. Journal of Wildlife Management 77:359-371.

McIntosh, T. E., R. C. Rosatte, J. Hamr, and D. L. Murray. 2009. Development of a sightability model for low-density elk populations in Ontario, Canada. Journal of Wildlife Management 73:580-585.

Pollock, K. H., and W. L. Kendall. 1987. Visibility bias in aerial surveys: a review of estimation procedures. Journal of Wildlife Management 51:502-510.

Rice, C. G., K. J. Jenkins, and W. Chang. 2009. A sightability model for mountain goats. Journal of Wildlife Management 73:468-478.

Riley, S. J., S. D. DeGloria, and R. Elliot. 1999. A terrain ruggedness index that quantifies topographic heterogeneity. Intermountain Journal of Sciences 5:1-4.

Samuel, M. D., E. O. Garton, M. W. Schlegel, and R. G. Carson. 1987. Visibility bias during aerial surveys of elk in Northcentral Idaho. Journal of Wildlife Management 51:622-630.

Sikes, R. S., W. L. Gannon, and the Animal Care and Use Committee of the American Society of Mammalogists. 2011. Guidelines of the American Society of Mammalogists for the use of wild mammals in research. Journal of Mammalogy 92:235-253.

Steidl, R. J. 2006. Model selection, hypothesis testing, and risks of condemning analytical tools. Journal of Wildlife Management 70:1497-1498.

Steinhorst, R. K., and M. D. Samuel. 1989. Sightability adjustment methods for aerial surveys of wildlife populations. Biometrics 45:415-425.

Texas Parks and Wildlife Department. 2007. Mule deer survey procedures. Texas Parks and Wildlife Department, Midland, USA.

Unsworth, J. W., F. A. Leban, E. O. Garton, D. J. Leptich, and P. Zager. 1999. Aerial survey: user's manual. Electronic edition. Idaho Department of Fish \& Game, Boise, USA.

U.S. Department of Agriculture, Farm Services Agency. 2014. National Agriculture Imagery Program (NAIP). http://www.fsa.usda.gov/FSA/ apfoapp?area $=$ home\&subject $=$ prog\&topic $=$ nai. Accessed 22 May 2015.

Walker, R. 2011. State status report. Western States and Provinces Deer and Elk Workshop Proceedings 9:46-64.

Walsh, D. P., C. F. Page, H. Campa III, S. R. Winterstein, and D. E. Beyer Jr. 2009. Incorporating estimates of group size in sightability models for wildlife. Journal of Wildlife Management 73:136-143.

Webb, S. L., J. S. Lewis, D. G. Hewitt, M. W. Hellickson, and F. C. Bryant. 2008. Assessing the helicopter and net-gun as a capture technique for white-tailed deer. Journal of Wildlife Management 72:310-314

White, G. C., R. M. Bartmann, L. H. Carpenter, and R. A. Garrott. 1989. Evaluation of aerial line transects for estimating mule deer densities. Journal of Wildlife Management 53:625-635.

White, G. C., and K. P. Burnham. 1999. Program MARK: survival estimation from populations of marked animals. Bird Study 46:120-139.

Williams, B. K., J. D. Nichols, and M. J. Conroy. 2002. Analysis and management of wildlife populations. Academic Press, San Diego, California, USA.

Associate Editor: Kelly Proffitt. 


\section{APPENDIX A}

Area $\left(\mathrm{km}^{2}\right)$ surveyed during repeated helicopter surveys for mule deer on 6 study sites in the Trans-Pecos (TP1-4) and Panhandle (PH1-2) regions of Texas, USA, January-February, 2008-2010.

\begin{tabular}{|c|c|c|c|c|c|c|c|c|c|c|}
\hline \multirow[b]{2}{*}{ Study site } & \multicolumn{9}{|c|}{ Survey no. } & \multirow[b]{2}{*}{$\bar{x}$} \\
\hline & 1 & 2 & 3 & 4 & 5 & 6 & 7 & 8 & 9 & \\
\hline TP1 & 22.0 & 28.2 & 25.1 & 28.3 & 24.6 & 29.1 & 33.5 & 35.0 & & 28.2 \\
\hline TP2 & 29.4 & 27.9 & 26.6 & 28.9 & 24.9 & 26.5 & 28.3 & 29.0 & & 27.7 \\
\hline TP3 & 30.3 & 34.4 & 25.2 & 36.7 & 31.1 & 32.9 & 20.9 & 32.9 & & 30.6 \\
\hline TP4 & 24.4 & 26.6 & 26.5 & 23.8 & 26.6 & 19.1 & 28.2 & 20.9 & & 24.5 \\
\hline PH1 & 24.6 & 30.2 & 24.3 & 29.2 & 28.9 & 28.3 & 27.9 & 27.1 & 26.9 & 27.5 \\
\hline PH2 & 26.0 & 28.9 & 32.0 & 39.7 & 35.6 & 39.7 & 30.6 & 32.9 & 32.9 & 33.1 \\
\hline
\end{tabular}

\section{APPENDIX B}

Number of marked mule deer available that were detected or not detected by individual variable during repeated helicopter surveys at 6 sites in the TransPecos and Panhandle regions of Texas, USA, January-February, 2008-2010.

\begin{tabular}{|c|c|c|c|c|}
\hline \multirow[b]{2}{*}{ Variable } & \multirow[b]{2}{*}{ States } & \multicolumn{2}{|c|}{ No. available } & \multirow[b]{2}{*}{ Proportion detected } \\
\hline & & Not detected & Detected & \\
\hline \multirow[t]{2}{*}{ Activity } & Inactive & 294 & 53 & 0.15 \\
\hline & Active & 534 & 527 & 0.50 \\
\hline \multirow[t]{10}{*}{ Distance $(\mathrm{m})$} & 0 & 70 & 138 & 0.66 \\
\hline & 9 & 54 & 58 & 0.52 \\
\hline & 18 & 66 & 8 & 0.11 \\
\hline & 27 & 93 & 133 & 0.59 \\
\hline & 36 & 77 & 53 & 0.41 \\
\hline & 45 & 86 & 45 & 0.34 \\
\hline & 55 & 93 & 44 & 0.32 \\
\hline & 64 & 100 & 42 & 0.30 \\
\hline & 73 & 90 & 22 & 0.20 \\
\hline & 81 & 99 & 37 & 0.27 \\
\hline \multirow[t]{2}{*}{ Cover type } & Open & 77 & 67 & 0.53 \\
\hline & Brush & 751 & 513 & 0.59 \\
\hline \multirow[t]{2}{*}{ Light } & Bright & 663 & 406 & 0.38 \\
\hline & Cloudy & 165 & 174 & 0.51 \\
\hline \multirow[t]{3}{*}{ Terrain } & Flat & 100 & 98 & 0.55 \\
\hline & Rolling & 367 & 360 & 0.53 \\
\hline & Rugged & 361 & 122 & 0.31 \\
\hline \multirow[t]{17}{*}{ Group size } & 1 & 44 & 217 & \\
\hline & 2 & 27 & 116 & \\
\hline & 3 & 10 & 73 & \\
\hline & 4 & 7 & 55 & \\
\hline & 5 & 2 & 38 & \\
\hline & 6 & & 30 & \\
\hline & 7 & 4 & 15 & \\
\hline & 8 & & 5 & \\
\hline & 9 & 1 & 6 & \\
\hline & 10 & & 7 & \\
\hline & 11 & & 3 & \\
\hline & 12 & & 6 & \\
\hline & 13 & & 1 & \\
\hline & 14 & & 3 & \\
\hline & 15 & & 1 & \\
\hline & 16 & & 1 & \\
\hline & 17 & & 1 & \\
\hline
\end{tabular}

\footnotetext{
${ }^{\text {a }}$ Group size was recorded for $11.7 \%$ of unobserved groups, so proportion detected was not calculated.
} 